\title{
Ultrasound and microwave assisted extraction of luteolin from Eclipta prostrata
}

\author{
Jun $\mathrm{Yi}^{1}$, Jian-Guo $\mathrm{Wu}^{2}$, Yan-Bin $\mathrm{Wu}^{2}$,Xiong-Hao $\mathrm{Lin}^{2}$ and Jin-Zhong $\mathrm{Wu}^{2 *}$ \\ ${ }^{1}$ Department of Science, Fujian institute of education, Fuzhou, Fujian 350001, China. \\ ${ }^{2}$ Academy of Integrative Medicine, Fujian University of Traditional Chinese Medicine, Fuzhou, Fujian 350108, China.
}

Accepted 3 December, 2012

\begin{abstract}
Luteolin (LU) is considered as one of the most important flavonoids with many beneficial functions to human health. In our present study, an efficient, convenient and reproducible extraction method of LU extracted from Eclipta prostrata by ultrasound assisted microwave extraction (UAME) was established. The extraction process of LU using UAME was optimized according to single factor test and orthogonal design, and the optimum parameters were obtained as follows: the ratio of $\mathbf{8 0 \%}$ ethanol, hydrochloric acid and plant material: 50: 0.3: 1 (v/v/w), microwave power: $40 \mathrm{~W}$, extracting time: $3 \times 3 \mathrm{~min}$. The extraction yield of LU was $0.690 \mathrm{mg} / \mathrm{g}$ under the optimum conditions, compared with heat reflux extraction (HRE) and reflux acid extraction (RAE) in terms of extraction yield, time consumption and labor intensiveness, indicating that the UAME was more efficient than RE and RAE. In conclusion, UAME could markedly reduce extraction time and simplify the extraction process of LU from E. prostrata.
\end{abstract}

Key words: Ultrasound assisted microwave acid extraction, luteolin, Eclipta prostrata L.

\section{INTRODUCTION}

Eclipta prostrata L. (Asteraceae) is one of the oldest tonic herbs in traditional Chinese medicine. Its aerial parts have been extensively used in China, Korea, India and Thailand for tonifying the liver and kidney, promoting the growth of hair, resisting hyperlipidemia, improving antioxidant and treating snake venom poisoning (Pithayanukul et al., 2004; Kumari et al., 2006; Roy et al., 2007; Kim et al., 2008; PCCn, 2010). Chemical constituent investigation indicates that $E$. prostrata is rich in flavonoids accounting for the beneficial functions on the human health (Zhang et al., 1997; Wang et al., 2009).

Among the flavonoids in E. prostrata, luteolin (LU, Chemical structure shown in Figure $1 \mathrm{a}$ ) is the main flavones possessing a wide spectrum of pharmacological properties including anti-amnesic (Liu et al., 2009), anti-tumorigenic (Lee et al., 2006; Samy et al., 2006; Du et al., 2008), anti-hepatotoxic (Domitrović et al., 2009), anti-

*Corresponding author. E-mail: jinzhongfj@126.com. Tel: +86 591-22861611. osteoporotic (Choi, 2007), anti-proliferative (Hou et al., 2009), anti-inflammatory (Choi, 2007; Leemans et al., 2010) and antioxidant activities (Horváthová et al., 2005; Ashokkumar et al., 2008). Thus, it prompted us to investigate the extraction technology of LU from $E$. prostrata previously.

Plant cell walls consist of cellulose, hemi-cellulose and pectin, which represent the barrier for the release of intracellular substances (Dong, 2010a). It was reported that the method of heat reflux extraction (HRE) has been used to extract LU from Herba Ecliptae associated with such undesirable traits as low yield, time consumption and labor intensiveness (Yang et al., 2008). Recently, Ultrasound assisted microwave extraction (UAME) has been used as an effective method to extract chemical constituents from plant materials (Zhang et al., 2008), which could accelerate the extracting process and improve the release of bioactive compounds (Martino et al., 2006; Fang et al., 2008; Golmakani and Rezaei, 2008; Huang et al., 2009). On the other hand, ultrasound can facilitate the solvation of plant materials by causing cell swelling and enlarging pores of the cell wall. Better swelling could 
improve the rate of mass transfer, resulting in the increased extraction efficiency and reduced extraction time (Dong, 2010b). Also, microwave extraction can heat the extracts quickly and accelerate the extraction process for adsorption and desorption of the targeted compounds from matrix but nevertheless, with the concomitant disadvantage of inhomogeneous heating (Bonrath, 2004).

This deficiency can be complemented by coupling microwave extraction with ultrasound (Zhang et al., 2008). Moreover, flavonoids are always occurring in combination with glucoses as glucosides with glucosidic linkages. When the glucosidic linkages were broken, free flavonoids were released (Fu et al., 2008). In order to obtain more free flavonoids, acids such as hydrochloric acid, sulphuric acid and perchloric acid are usually used to break the glucosidic linkages (Dong, 2010c).

The objective of the present study was to investigate the effect of ultrasound assisted microwave on the extraction of LU from E. prostrata. Several parameters affecting UAME of LU, that is, types of solvent, ratio of hydrochloric acid to solvent, ratio of solvent to material, microwave power and extraction time were optimized according to single factor test and orthogonal design. Ultimately, to better understand the advantages of UAME, we also compared it with heat reflux extraction (HRE) and reflux acid extraction (RAE) methods.

\section{MATERIALS AND METHODS}

\section{Plant}

The herb of $E$. prostrata was purchased from Tianren Pharmaceutical Company (Fujian, China) and identified as the aerial parts of E. prostrata by Cheng-Zi Yang, Department of Pharmacy, Fujian University of Traditional Chinese Medicine, Fuzhou, China. Then, voucher specimen was deposited in the herbarium of Academy of Integrative Medicine, Fujian University of Traditional Chinese Medicine, Fuzhou, China. Samples were dried in vacuum oven at $40^{\circ} \mathrm{C}$, then ground and sieved for homogenization ( 40 mesh). The ground samples were kept in a dry place prior to use.

\section{Chemicals and reagents}

Luteolin (LU, 3',4',5,7-tetrahydroxyflavone) standard was purchased from the Chengdu Mansite Pharmacetical Co. Ltd. (Sichuan, China) with a purity $>98 \%$. The standard was dissolved in methanol to obtain the stock solution at concentration of $0.2 \mathrm{mg} / \mathrm{mL}$ for $\mathrm{LU}$. Methanol of High-performance liquid chromatography (HPLC) grade was purchased from Sinopharm Chemical Reagent Co. Ltd. (Shanghai, China). Ethanol, methanol, sodium hydroxide and hydrochloric acid $(12 \mathrm{~mol} / \mathrm{L})$ of analytical grade were obtained from Fuchen Chemicals Reagent Factory (Tianjin, China). Deionized water was purified by a Milli-Q water-purification system from Millipore (Bedford, MA, USA).

\section{Instrument and analytical conditions}

UAME experiment was performed with an ultrasonic and microwave extracting apparatus (CW-2000, Shanghai Xintuo Analytical Instru- ments Co., LTD). An open microwave with maximal power of $800 \mathrm{~W}$ at a frequency of $2450 \mathrm{MHz}$, and an ultrasonic transducer with a fixed power of $50 \mathrm{~W}$ at a frequency of $40 \mathrm{KHz}$ were the conditions of extraction. The determination of LU was carried out on a Waters liquid chromatographic system (Waters Company, USA) consisting of Masslynx 4.0 system software, Model Waters Delta 600 pump and Model Waters 2996 Photodiode Array Detector (PAD). Chromatographic separation was carried out by Ultrasphere ODS C18 reversed-phase column $(4.6 \times 150 \mathrm{~mm}$, BECKMAN Corporation, USA) packed with $5 \mu \mathrm{m}$ diameter particles. LU was quantified by a PAD at $352 \mathrm{~nm}$ following Reversed phase-high performance liquid chromatography (RP-HPLC) separation. The mobile phase was methanol $0.4 \%$ phosphoric acid $(45: 55, \mathrm{v} / \mathrm{v})$, which was filtered through a $0.45 \mu \mathrm{m}$ membrane filter and then deaerated ultrasonically prior to use. The flow rate was $1 \mathrm{~mL} / \mathrm{min}$, the injection volume was $10 \mu \mathrm{L}$, the column temperature was maintained at $30^{\circ} \mathrm{C}$ and the retention time for LU was $11.5 \mathrm{~min}$. Chromatographic peaks of LU was confirmed by comparing their retention time and UV spectrum with the reference compound. The working calibration curve based on reference compound of LU showed good linearity over the range of 10 to $200 \mu \mathrm{g} / \mathrm{mL}$. The regression line was $Y=14630 X-630.14\left(R^{2}=0.9998, n=7\right)$, where $Y$ is the peak area of analysis, and $X$ is the concentration of reference compound $(\mu \mathrm{g} / \mathrm{mL})$.

\section{Different extraction methods}

\section{Optimums of the extraction parameters of UAME}

According to $\mathrm{LU}$ yield of the extraction from E. prostrata, the optimum extraction parameters of UAME were investigated. The ultrasonic and microwave extracting apparatus was used to extract LU from E. prostrata: the sample (about $2 \mathrm{~g}$ ) was transferred into the flask, proper volume (assigned according to the experiment planning) of the extraction solvent added and then the flask was transferred into the chamber of the apparatus connected with a condensing tube. Finally, the door of chamber was closed and the program of the parameters (microwave power and extraction time) was set according to the experimental design. After the process was finished, the flask was removed from apparatus. The mixture was filtered through filter paper immediately and evaporated to dryness by removing the solvent in a rotary evaporator (RE-52, Shanghai splendor and biochemical instrument Co., China) at $40^{\circ} \mathrm{C}$ under reduced pressure.

If the solvent containing hydrochloric acid was used to extract, the extracts were neutralized by sodium hydroxide solution $(5 \mathrm{~mol} / \mathrm{L})$ before the solvent evaporation. After cooling, the extract dissolved in methanol was transferred to a $10 \mathrm{~mL}$ volumetric flask and diluted with methanol to volume. The obtained sample solution was then passed through a $0.45 \mu \mathrm{m}$ Millipore membrane prior to HPLC analysis.

Single factor and orthogonal experiments were performed to optimize the extraction condition of LU from E. prostrata using UMAE. Firstly, the effects of solvent type (water/methanol/ethanol), ethanol concentration (20 to $100 \% \mathrm{v} / \mathrm{v}$ ), ratio of hydrochloric acid (12 $\mathrm{mol} / \mathrm{L})$ to solvent $(0.006$ to $0.024 \mathrm{v} / \mathrm{v})$, ratio of solvent to material (20:1 to $50: 1 \mathrm{v} / \mathrm{w})$, microwave power (10 to $50 \mathrm{~W}$ ) and extraction time (120 to $360 \mathrm{~s}$ ) on the extraction yield of LU from E. prostrata were investigated, respectively. Secondly, an orthogonal test was designed to optimize the extraction parameters depending on the results of the single factor experiments. The factors and levels tested in this study were presented in Table 1 . The orthogonal test design consisted of sixteen separate experiments in Table 2. The sequence of the experiments was randomized to ensure the validity of the test results. The statistical software Statistical Package for the 
Table 1. Independent factors and levels of orthogonal test by UAME.

\begin{tabular}{ccccc}
\hline \multirow{4}{*}{ Level } & \multicolumn{4}{c}{ Independent factors } \\
\cline { 2 - 5 } & $\begin{array}{c}\text { Ethanol } \\
\text { concentration (\%) }\end{array}$ & $\begin{array}{c}\text { Ratio of solvent } \\
\text { to material (v/w) }\end{array}$ & $\begin{array}{c}\text { Extraction } \\
\text { power (w) }\end{array}$ & $\begin{array}{c}\text { Extraction } \\
\text { time (s) }\end{array}$ \\
\hline 1 & 20 & 20 & 10 & 180 \\
2 & 40 & 30 & 20 & 240 \\
3 & 60 & 40 & 30 & 300 \\
4 & 80 & 50 & 40 & 360 \\
\hline
\end{tabular}

Table 2. Orthogonal test design and results by UAME.

\begin{tabular}{|c|c|c|c|c|c|}
\hline \multirow[b]{2}{*}{ Test no. } & \multicolumn{4}{|c|}{ Factor and level } & \multirow[b]{2}{*}{ Extraction yield of $L U(\mathrm{mg} / \mathrm{g})$} \\
\hline & $\begin{array}{c}\text { Ethanol } \\
\text { concentration }\end{array}$ & $\begin{array}{c}\text { Ratio of solvent } \\
\text { to material }\end{array}$ & $\begin{array}{c}\text { Extraction } \\
\text { power }\end{array}$ & $\begin{array}{c}\text { Extraction } \\
\text { time }\end{array}$ & \\
\hline 1 & 1 & 1 & 1 & 1 & 0.166 \\
\hline 2 & 1 & 2 & 2 & 2 & 0.174 \\
\hline 3 & 1 & 3 & 3 & 3 & 0.195 \\
\hline 4 & 1 & 4 & 4 & 4 & 0.345 \\
\hline 5 & 2 & 1 & 2 & 3 & 0.207 \\
\hline 6 & 2 & 2 & 1 & 4 & 0.309 \\
\hline 7 & 2 & 3 & 4 & 1 & 0.532 \\
\hline 8 & 2 & 4 & 3 & 2 & 0.553 \\
\hline 9 & 3 & 1 & 3 & 4 & 0.285 \\
\hline 10 & 3 & 2 & 4 & 3 & 0.551 \\
\hline 11 & 3 & 3 & 1 & 2 & 0.570 \\
\hline 12 & 3 & 4 & 2 & 1 & 0.562 \\
\hline 13 & 4 & 1 & 4 & 2 & 0.477 \\
\hline 14 & 4 & 2 & 3 & 1 & 0.524 \\
\hline 15 & 4 & 3 & 2 & 4 & 0.629 \\
\hline 16 & 4 & 4 & 1 & 3 & 0.588 \\
\hline$T_{1}$ & 0.880 & 1.135 & 1.633 & 1.784 & \\
\hline$T_{2}$ & 1.601 & 1.558 & 1.572 & 1.774 & \\
\hline$T_{3}$ & 1.968 & 1.926 & 1.272 & 1.541 & \\
\hline$T_{4}$ & 2.218 & 2.048 & 1.905 & 1.568 & \\
\hline $\mathrm{K}_{1}$ & 0.220 & 0.284 & 0.408 & 0.446 & \\
\hline $\mathrm{K}_{2}$ & 0.400 & 0.390 & 0.393 & 0.444 & \\
\hline $\mathrm{K}_{3}$ & 0.492 & 0.482 & 0.318 & 0.385 & \\
\hline $\mathrm{K}_{4}$ & 0.555 & 0.512 & 0.476 & 0.392 & \\
\hline $\mathrm{R}^{\mathrm{a}}$ & 0.335 & 0.228 & 0.158 & 0.061 & \\
\hline
\end{tabular}

${ }^{\mathrm{a}}$ Extreme difference (range).

Social Sciences (SPSS) 18.0 was used to calculate the result of variance analysis (Table 3).

\section{Comparison of luteolin yields extracted from $E$. prostrata by UAME, HRE and RAE}

The HRE method was widely used in the field of medicine, food and light industry. However, HRE, which is due to using a large volume of a solvent and spending a lot of time, may gradually be substituted by some modern extraction methods, such as ultrasonic and microwave, supercritical fluid extraction, and so on. In our paper, UAME, HRE, and RAE were used to extract LU from E. prostrata, respectively. Each test was two repeats and the result of LU yield was an average of two times. To enhance $L U$ yield, hydrochloric acid was added to the solvent of extraction. HRE was done such that the extracts mixed with hydrochloric acid after the extraction of LU from E. prostrata. Both UAME and RAE were done such that the 
Table 3. Analysis of variance (ANOVA) table for the orthogonal experiment.

\begin{tabular}{lccccc}
\hline Source of variance & Sum of square & $\boldsymbol{d f}$ & Mean square & F-value & Significance \\
\hline Ethanol concentration & 0.255 & 3 & 0.085 & 13.180 & $*$ \\
Ratio of solvent to material & 0.127 & 3 & 0.042 & 6.551 & \\
Extraction power & 0.020 & 3 & 0.007 & 1.022 & \\
Extraction time & 0.013 & 3 & 0.004 & 0.656 & \\
Error & 0.019 & 3 & 0.006 & & \\
Total & 0.434 & 15 & & & \\
\hline
\end{tabular}

*Significant $(p<0.05), d f=$ difference

Table 4. Comparison of the results among UAME, HRE and RAE $(n=2)$.

\begin{tabular}{lccccccc}
\hline Extraction method & & UAME & & HRE & \multicolumn{3}{c}{ RAE } \\
\hline Number of extraction cycles & 1 & 2 & 3 & 2 & 1 & 1 & 1 \\
Total extraction time (min) & 3 & 6 & 9 & 240 & 30 & 60 & 120 \\
Total solvent amount $(\mathrm{mL})$ & 100 & 200 & 300 & 300 & 300 & 300 & 300 \\
Extraction yield $(\mathrm{mg} / \mathrm{g})$ & 0.632 & 0.676 & 0.690 & 0.676 & 0.600 & 0.689 & 0.653 \\
\hline
\end{tabular}

solvent containing hydrochloric acid was used to extract LU from $E$. prostrata. All of their procedures were as follows.

\section{UAME}

The powder of $E$. prostrata (about $2 \mathrm{~g}$ ) was mixed with $100 \mathrm{~mL}$ of $80 \%$ ethanol containing $0.6 \mathrm{~mL}$ hydrochloric acid $(12 \mathrm{~mol} / \mathrm{L})$ at $40 \mathrm{~W}$ for $3 \mathrm{~min}$ in each extraction cycle (Table 4). The procedure of extraction was the same as "Optimums of the extraction parameters of UMAE" instruction in this paper.

\section{HRE}

The powder of $E$. prostrasta (about $2 \mathrm{~g}$ ) was mixed with $150 \mathrm{~mL}$ of $80 \%$ ethanol, and loaded into a flask equipped with a water condenser tube. The extraction solvents were boiled $\left(80 \pm 2^{\circ} \mathrm{C}\right)$ and refluxed for a period of $120 \mathrm{~min}$. Extraction was repeated twice and the total solvent amount was $300 \mathrm{~mL}$. The combined extracts were filtered through filter paper. Afterwards, the filtrate was hydrolyzed by $1.8 \mathrm{~mL}$ hydrochloric acid $(12 \mathrm{~mol} / \mathrm{L})$ in a water-bath $\left(80 \pm 2^{\circ} \mathrm{C}\right)$ for $1 \mathrm{~h}$ and neutralized by sodium hydroxide solution $(5 \mathrm{~mol} / \mathrm{L})$ then the same procedures were adopted as described in the UAME.

\section{RAE}

The powder of $E$. prostrata (about $2 \mathrm{~g}$ ) was mixed with $300 \mathrm{~mL}$ of $80 \%$ ethanol containing $1.8 \mathrm{~mL}$ hydrochloric acid (12 mol/L), and was placed into a flask equipped with a water condenser tube. The extraction solvents were boiled $\left(80 \pm 2^{\circ} \mathrm{C}\right)$. Three samples were repeated in Table 4. Their reflux times were 30,60 and $120 \mathrm{~min}$, respectively. After that, the same procedures were adopted as described in UAME.

\section{RESULTS AND DISCUSSION}

\section{Chromatographic results}

Identification of the LU was carried out by comparing its retention time and on-line UV spectrum. As shown in Figure 1a, the chromatograms of standard showed the standard substance with retention time of $11.5 \mathrm{~min}$ for LU. In Figure $1 \mathrm{~b}$, the chromatograms of $E$. prostrata extracts by UAME (Figure 1b1), HRE (Figure 1b2) and RAE (Figure 1b3) were presented. These results indicated that different extraction methods possessed similar chromatographic characteristic and contained the standard substance of LU.

\section{Effects of extraction variables on extraction yield of LU}

\section{Selection of solvent}

The extraction follows the principle of "like dissolves like". Low polarity solvent yields more lipophilic components, while alcoholic solvent gives a larger spectrum of apolar and polar compounds (Stecher et al., 2003). LU possesses a planar structure and has the molecular close packing, so its solution in water is little (Dong, 2010d). However, LU has four phenol hydroxyls, it shows certain polar degree. Therefore, water, methanol and ethanol were used to extract LU from E. prostrata in this study. Figure 2 shows the effects of different solvents on the 

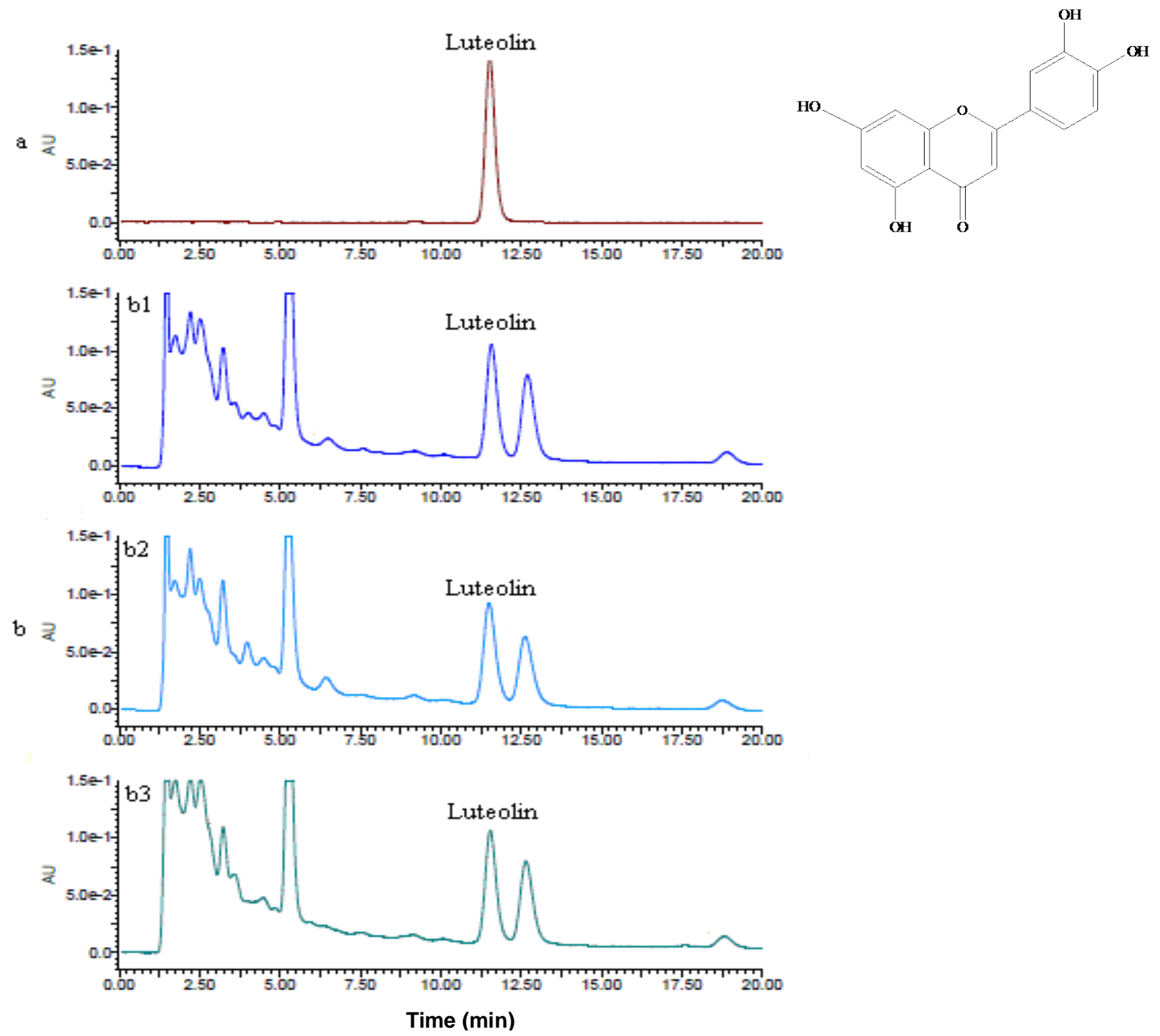

Figure 1. Chromatograms of standard substance and samples by HPLC-UV detected at $352 \mathrm{~nm}$ : (a) standard substance and structure; (b) Eclipta prostrata extracts: (b1) UAME, (b2) HRE, (b3) RAE.

extraction yield of LU from the powder of $E$. prostrata. The extraction conditions were as follows: ratio of solvent to material: $20: 1$, ratio of hydrochloric acid to solvent: 0.006 , microwave power: $30 \mathrm{~W}$, and the extraction time: $180 \mathrm{~s}$. Under the same extraction conditions, five different extraction solvents that is, water, methanol, $80 \%$ methanol, ethanol and $80 \%$ ethanol exhibited different efficiency on the extraction yield of the objective constituent as shown in Figure 2, which might be mainly due to their different polarity. According to the result, the yield of LU extracted by different extraction solvents followed this order: $80 \%$ ethanol $>80 \%$ methanol $\approx$ methanol > ethanol > water. $80 \%$ ethanol was found to be the best extraction solvent with the highest yield of 0.53 $\mathrm{mg} / \mathrm{g}$. Therefore, it was chosen as the extraction solvent.

In order to gain the optimized extraction aqueous ethanol solvent, the effects of different concentrations of ethanol on the extraction yield of LU was investigated. As shown in Figure 3, when the ethanol content is less than $80 \%$, the yield of $\mathrm{LU}$ increased with increased ethanol content. However, absolute ethanol did not show the highest yield and $80 \%$ ethanol was verified to be the optimized extraction solvent with the highest extraction yield of LU $(0.53 \mathrm{mg} / \mathrm{g})$. This is probably due to the solvent-solute affinity and the effective swelling of the plant material by the solvent, which can increase the 


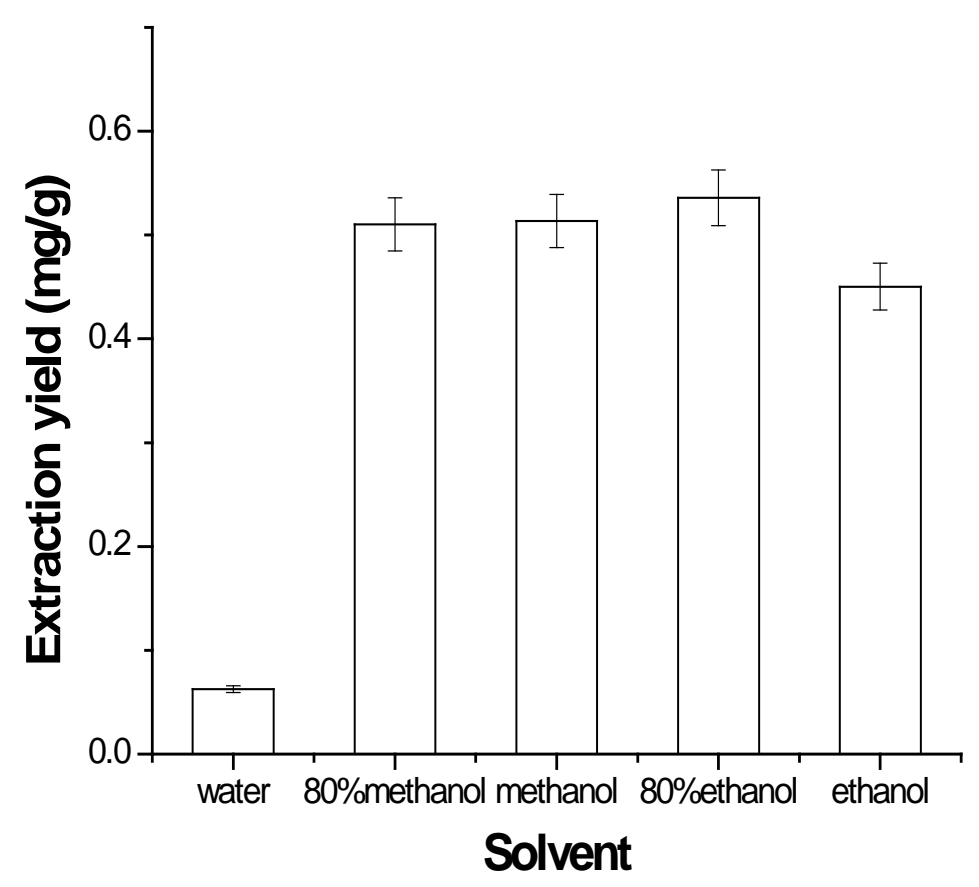

Figure 2. Effects of different solvents on the extraction yield of LU from $E$. prostrata. ratio of solvent to material ( $\mathrm{v} / \mathrm{w})$ : $20: 1$; ratio of hydrochloric acid to solvent (v/v): 0.006; microwave power: $30 \mathrm{~W}$; extraction time: $180 \mathrm{~s}$.

surface area for solute-solvent contact (Li et al., 2004).

\section{Ratio of hydrochloric acid to aqueous ethanol}

Hydrochloric acid can facilitate the release of flavonoids by breaking the hydrogen bonding interactions and glucosidic linkages (Dong, 2010c). Thus, the effect of ratio of hydrochloric acid $(12 \mathrm{~mol} / \mathrm{L})$ to solvent $(\mathrm{v} / \mathrm{v})$ on the extraction yield of LU was investigated in our present study. As shown in Figure 4, the extraction yield increased when ratio of hydrochloric acid to solvent ranged from 0 to $0.006(\mathrm{v} / \mathrm{v})$, then became fairly constant when ratio of hydrochloric acid to solvent was above $0.006(\mathrm{v} / \mathrm{v})$. Hence, the ratio of hydrochloric acid to solvent was set at 0.006 $(\mathrm{v} / \mathrm{v})$.

\section{Ratio of aqueous ethanol to material}

Generally, a larger solvent volume can dissolve target components more effectively leading to an improvement of the extraction yield. However, this will lead to excess work in the concentration process, resulting in the unnecessary waste of solvent and time. To obtain the optimum volume of extraction solvent, we observed the effect of ratio of solvent to material $(\mathrm{v} / \mathrm{w})$ on the extraction yield of LU. As presented in Figure 5, the result indicated that ratio of solvent to material $(50: 1)$ should be suitable for the extraction of LU from $E$. prostrata.

\section{Extraction time}

Extraction time is another important factor in extraction procedures. Before the establishment of the equilibrium between the objective constituents in and out the plant cells, the yield of extraction increases with time. However, it will not increase with time after the establishment of the equilibrium (Fang et al., 2008). Figure 6 shows the effect of extraction time on the extraction efficiency of LU. The extraction yield of LU slightly increased when the extraction time was extended from 120 to $300 \mathrm{~s}$, and it decreased along with time when the extraction time was longer than $300 \mathrm{~s}$. This may be due to ionization, hydrolysis and oxidation during extraction with increasing the extraction time (Li et al., 2005). Therefore, longer time of extraction is unnecessary after the maximum extraction yield is achieved.

\section{Microwave power}

The samples of E. prostrata were extracted for $180 \mathrm{~s}$ with different extraction power, respectively. Figure 7 shows the effects of microwave power on the extraction 


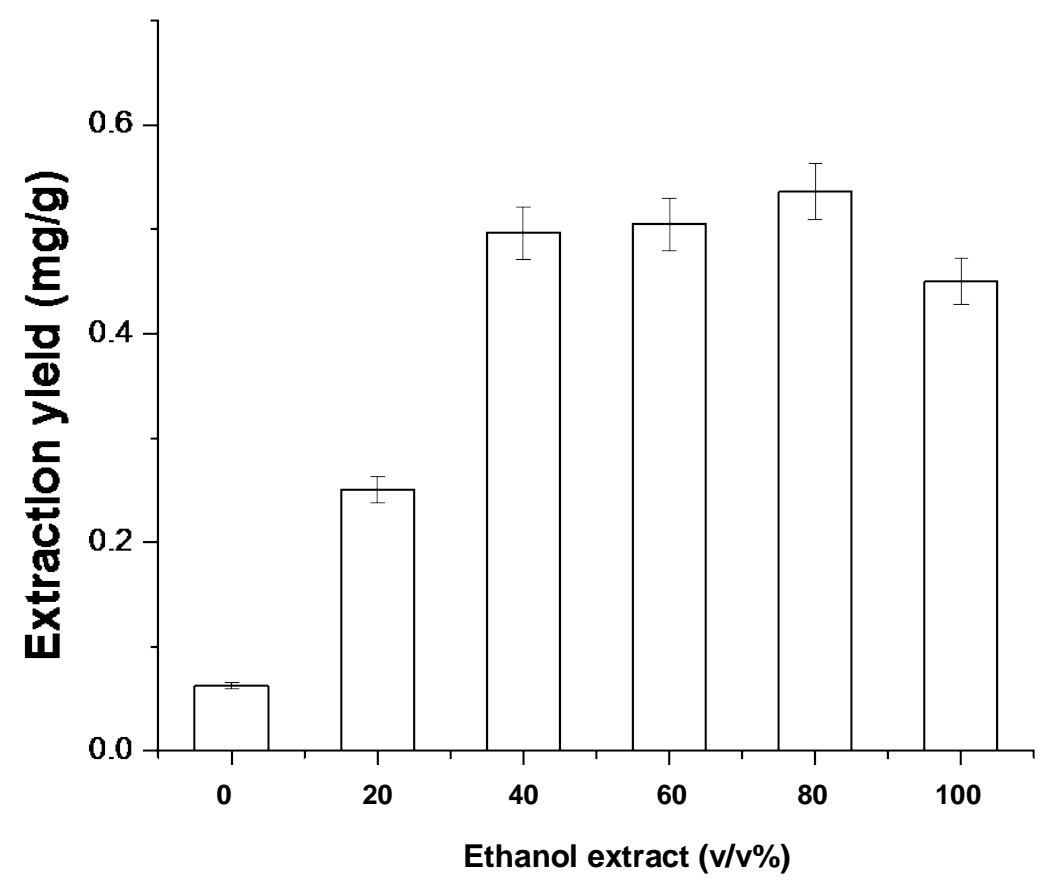

Figure 3. Effects of different concentrations of aqueous ethanol on the extraction yield of LU from Eclipta prostrata. Ratio of solvent to material (v/W): 20:1; ratio of hydrochloric acid to solvent ( $\mathrm{v} / \mathrm{v})$ : 0.006; microwave power: $30 \mathrm{~W}$; extraction time: $180 \mathrm{~s}$.

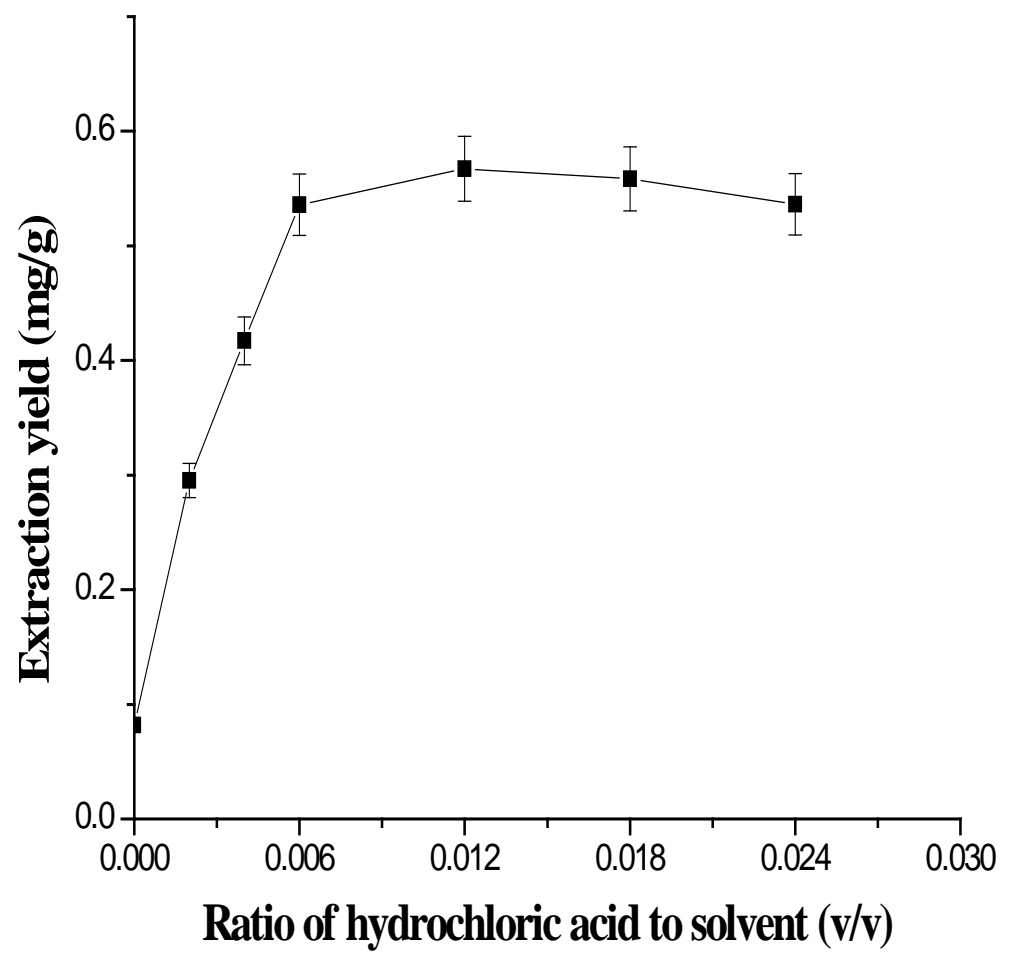

Figure 4. Effect of ratio of hydrochloric acid to solvent $(\mathrm{v} / \mathrm{v})$ on the extraction yield of LU from Eclipta prostrata. Ethanol concentation $(\mathrm{v} / \mathrm{v})$ : $80 \%$; ratio of solvent to materia (v/w): 20:1; microwave power: $30 \mathrm{~W}$; extraction time: $180 \mathrm{~s}$. 


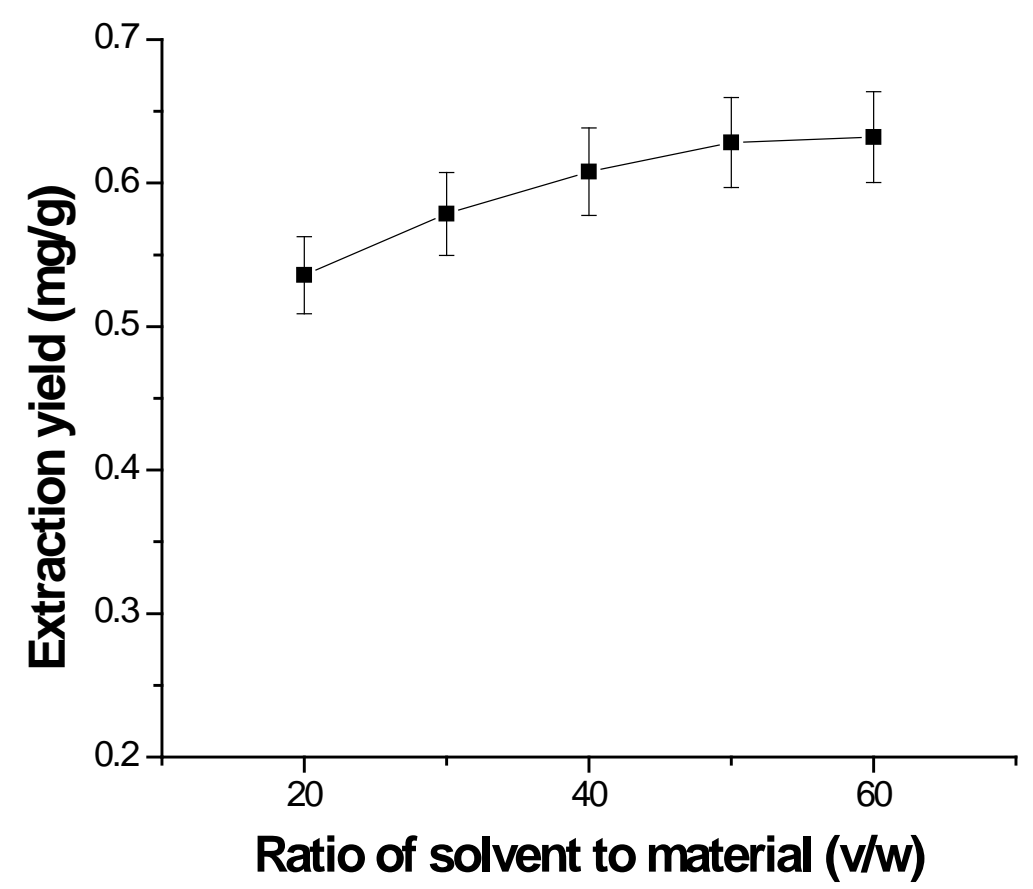

Figure 5. Effect of ratio of solvent to material on the extraction yield of LU from Eclipta prostrata. Ethanol concentation (v/v): $80 \%$; ratio of hydrochloric acid to solvent (v/v): 0.006; microwave power: $30 \mathrm{~W}$; extraction time: $180 \mathrm{~s}$.

efficiency of LU. As shown in Figure 7, the extraction yield increased with increased microwave power from 10 to 40 $\mathrm{W}$. This may be ascribed with the acoustic cavitation bubble size increase with increasing acoustic power (Adam et al., 2009). However, when the extraction power was set above $40 \mathrm{~W}$, the extraction yield starts to decrease. This suggests that a relatively stronger acoustic power was crucial to the chemical structures of components, leading to a lower extraction yield because the cavitation causes a great deal of noise and damage to components (Durmus et al., 2008).

\section{Orthogonal experiment}

Based on the above results from single factor experiments, an orthogonal experiment $\left(\mathrm{L}_{16}\left(4^{5}\right)\right)$ of UAME of LU was designed in order to optimize the combination of parameters. Four factors, ethanol concentration, ratio of solvent to material, microwave power and extraction time were selected for optimization (Table 1). For four factors at four levels each, the orthogonal test design required only 16 experiments while the traditional full factorial design would require 256 experiments. The results of orthogonal experiment and extreme difference analysis were presented in Table 2, and the result of variance analysis calculated by the statistical software SPSS 18.0 is listed in Table 3.
The analysis of extreme difference indicated that the influential order of the four factors on the extraction yield of $\mathrm{LU}$ was ethanol concentration $>$ ratio of solvent to material $>$ microwave power $>$ extraction time (Table 2). The order is in agreement with the order based on the values of $F$ in variance analysis (Table 3). According to variance analysis, the contribution of ethanol concentration for the extraction yield of $L U$ is significant $(P$ $<0.05$ ), whereas ratio of solvent to material, microwave power and extraction time are not significant factors. In the orthogonal test, the higher extraction yield $(0.629$ $\mathrm{mg} / \mathrm{g}$ ) in the fifteenth experiment provided evidence that the deduced extraction condition might be the optimum one. To reconfirm this deduced optimum condition, UAME under this condition was carried out, and the extraction yield of luteolin reached $0.632 \mathrm{mg} / \mathrm{g}$. So, this deduced condition was rationally confirmed to be the best combination of different parameters.

\section{Comparison of luteolin yields extracted from $E$. prostrata by UAME, HRE and RAE}

In Table 4, the LU yields extracted from E. prostrata by UAME increased with the number of extraction cycles. The LU yields of one cycle, two cycles and three cycles were $0.632,0.676,0.690 \mathrm{mg} / \mathrm{g}$, respectively. It was evident that most of LU was extracted from $E$. prostrata in 


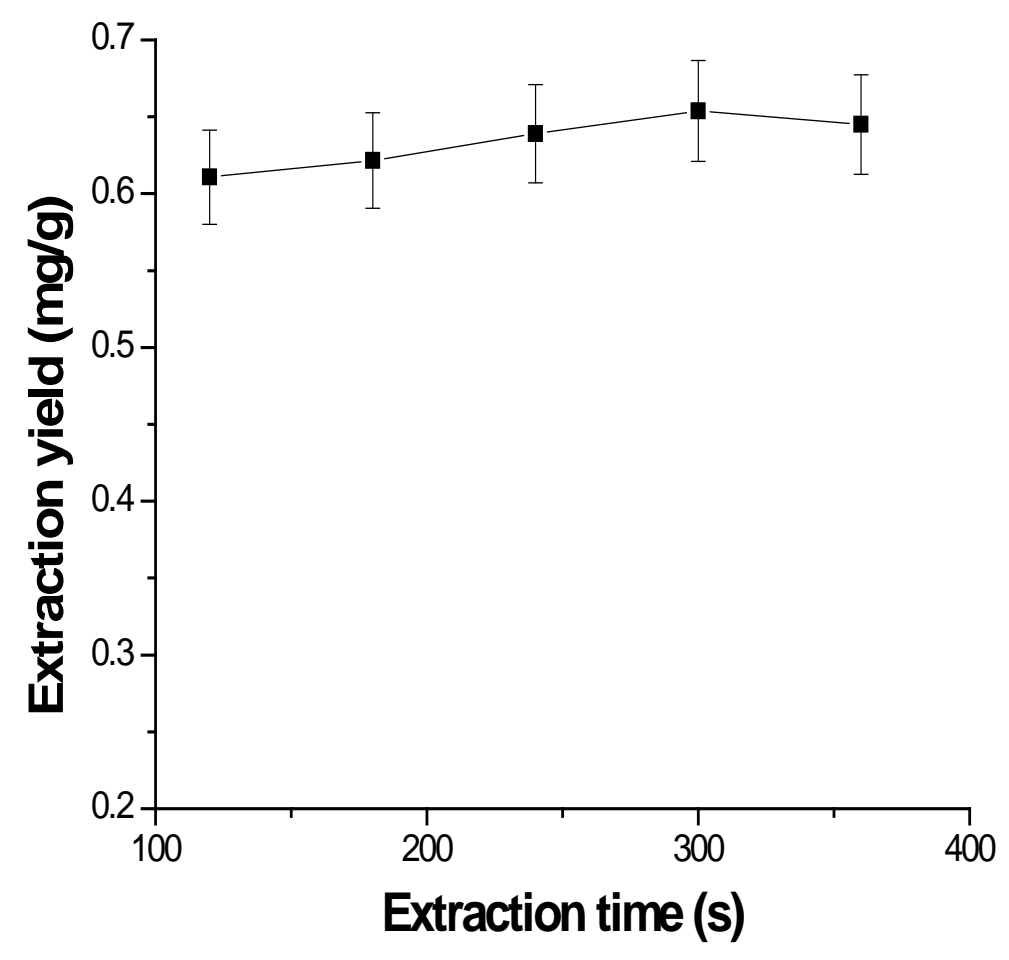

Figure 6. Effect of the extraction time on the extraction yield of $\mathrm{LU}$ from Eclipta prostrata. Ethanol concentation (v/v): $80 \%$; ratio of hydrochloric acid to solvent $(\mathrm{v} / \mathrm{v})$ : 0.006 ; ratio of solvent to material $(\mathrm{v} / \mathrm{w})$ : $50: 1$; microwave power: $40 \mathrm{~W}$.

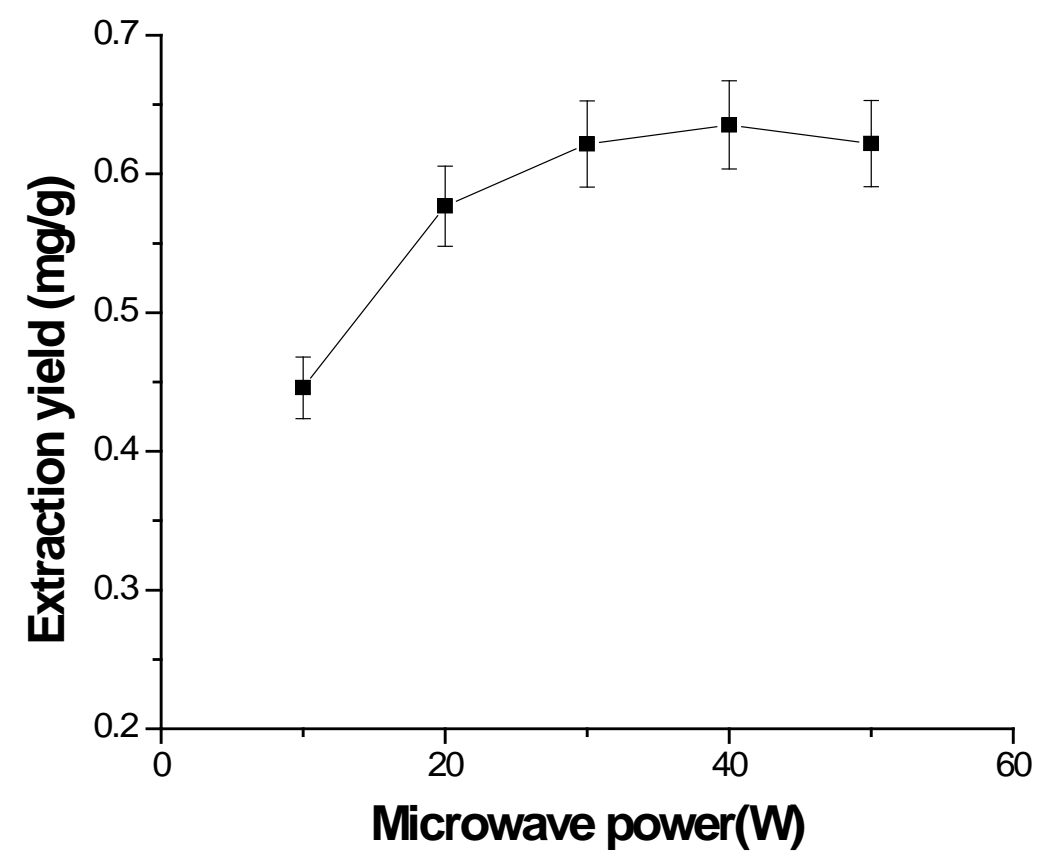

Figure 7. Effect of the microwave power on the extraction yield of LU from Eclipta prostrata. Ethanol concentation (v/v): $80 \%$; ratio of hydrochloric acid to solvent $(\mathrm{v} / \mathrm{v})$ : 0.006 ; ratio of solvent to material $(\mathrm{v} / \mathrm{w})$ : $50: 1$; extraction time: 180 s. 
one cycle by UAME. Based on these results, it should be weighed to ascertain whether further extraction after the first cycle is to be continued or not, because of the solvent consumption increasing with the extraction times. To evaluate the advantages of UAME, the comparison of LU yields extracted by UAME, HRE and RAE were carried out under the same solvent consumption $(300 \mathrm{~mL})$. After 9 min extraction (three extraction cycles), UAME could produce the similar extraction yield $(0.690 \mathrm{mg} / \mathrm{g})$ as $\mathrm{HRE}$ after $240 \mathrm{~min}$ (two extraction cycles) $(0.676 \mathrm{mg} / \mathrm{g}$ ) and RAE after $60 \mathrm{~min}(0.689 \mathrm{mg} / \mathrm{g})$.

The results showed that the extraction time of UAME were significantly shorter than that of HRE and RAE. From the above, it was evident that UAME is a more attractive extracting method when compared with HRE and RAE in terms of extraction yield, time consumption and labor intensiveness.

\section{CONCLUSION}

The extraction process of LU from E. prostrata by UAME was optimized using single factor test and orthogonal design. The optimal extraction condition of UAME was gained as follows: the ratio of $80 \%$ ethanol, hydrochloric acid and plant material: 50: 0.3: $1(\mathrm{v} / \mathrm{v} / \mathrm{w})$, microwave power: $40 \mathrm{~W}$ and extraction time: $3 \times 3 \mathrm{~min}$. Moreover, ethanol content affected significantly on the extraction yield of $L U(P<0.05)$. The extraction yield of $L U$ was $0.690 \mathrm{mg} / \mathrm{g}$ under the optimum conditions, compared with HRE and RAE in terms of extraction yield, time consumption and labor intensiveness, indicating that the UAME was more efficient than HRE and RAE.

\section{Conclusion}

UAME could markedly reduce extraction time, simplify the extraction process and gain higher $L U$ yield from $E$. prostrata

\section{ACKNOWLEDGEMENTS}

This work was conducted in Class III Laboratory of Traditional Chinese Medicine on Pharmacognosy of State Administration of Traditional Chinese Medicine of People's Republic of China and was financially supported by Key Project of Fujian Provincial Universities for Haixi Development (No. 5), the Research Foundation of Education Bureau of Fujian Province of China (No. JA10181), the Research Foundation of Health Bureau of Fujian Province of China (No. 2011-1-39) and the Natural Science Foundation of Fujian province of China (No. 2011J01214).

\section{REFERENCES}

Adam B, Franz G, Muthupandian A (2009). Effect of Power and Frequency on Bubble-Size Distributions in Acoustic Cavitation. Phys. Rev. Lett. 102:084302.

Ashokkumar P, Sudhandiran G (2008). Protective role of luteolin on the status of lipid peroxidation and antioxidant defense against azoxymethane-induced experimental colon carcinogenesis. Biomed. Pharmacother. 62:590-597.

Bonrath W (2004). Chemical reactions under "non-classical conditions", microwaves and ultrasound in the synthesis of vitamins. Ultrason. Sonochem. 11:1-4.

Choi E (2007). Modulatory effects of luteolin on osteoblastic function and inflammatory mediators in osteoblastic MC3T3-E1 cells. Cell Biol. Int. 31:870-877.

Domitrović R, Jakovac H, Milin C, Radosević-Stasić B (2009). Dose- and time-dependent effects of luteolin on carbon tetrachloride-induced hepatotoxicity in mice. Exp. Toxicol. Pathol. 61:581-589

Dong XP (Eds.) (2010a). Natural Medicinal Chemistry. Beijing: CPTCM Press. pp. 14-15.

Dong XP (Eds.) (2010b). Natural Medicinal Chemistry. Beijing: CPTCM Press. p. 18.

Dong XP (Eds.) (2010c). Natural Medicinal Chemistry. Beijing: CРTCM Press. pp. 6-97.

Dong XP (Eds.) (2010d). Natural Medicinal Chemistry. Beijing: CPTCM Press. pp. 165-166.

Du GJ, Song ZH, Lin HH, Han XF, Zhang S, Yang YM (2008). Luteolin as a glycolysis inhibitor offers superior efficacy and lesser toxicity of doxorubicin in breast cancer cells. Biochem. Biophysl. Res. commun. 372:497-502.

Durmus Kaya E. Alptekin Yagmur K. Suleyman Y, Fatma CK, Salih Eren A, Cenk C (2008). Energy efficiency in pumps. Energy Conversion and Management. 49:1662-1673

Fang W, Gao GZ, Wang XF, Dong XY, Li PP, Wei H, Xu W, Wu XM, Hong $C$ (2008). Quantitative determination of oil content in small quantity of oilseed rape by ultrasound-assisted extraction combined with gas chromatography. Ultrason. Sonochem. 15:938-942.

Fu YJ, Liu W, Zu YG, Tong MH, Li SM, Yan MM, Thomas Efferth, Luo H (2008). Enzyme assisted extraction of luteolin and apigenin from pigeonpea[Cajanus cajan(L.) Millsp.] leaves. Food Chem. 111:508-512.

Golmakani MT, Rezaei K (2008). Comparison of microwave-assisted hydrodistillation with the traditional hydrodistillation method in the extraction of essential oils from Thymus vulgaris L. Food. Chem. 109:925-930.

Horváthová K, Chalupa I, Sebová L, Tóthová D, Vachálková A (2005). Protective effect of quercetin and luteolin in human melanoma HMB-2 cells. Mutat. Res. 565:105-112.

Hou Y, Wu J, Huang Q, Guo L (2009). Luteolin inhibits proliferation and affects the function of stimulated rat synovial fibroblasts. Cell Biol. Int. 33:135-147.

Huang W, Xue A, Niu H, Jia Z, Wang JW (2009). Optimization and comparison of ultrasound/microwave assisted extraction (UMAE) and ultrasonic assisted extraction (UAE) of lycopene from tomatoes. Food. Chem. 114:1147-1154.

Kim DI, Lee SH, Choi JH, Lillehoj HS, Yu MH, Lee GS (2008). The butanol fraction of Eclipta prostrata (Linn) effectively reduces serum lipid levels and improves antioxidant activities in CD rats. Nutr. Res. 28:550-554.

Kumari CS, Govindasamy S, Sukumar E (2006). Lipid lowering activity of Eclipta prostrate in experimental hyperlipidemia. J. Ethnopharmacol. 105:332-335.

Lee WJ, Wu LF, Chen WK, Wang CJ, Tseng TH (2006). Inhibitory effect of luteolin on hepatocyte growth factor/scatter factor-induced HepG2 cell invasion involving both MAPK/ERKs and PI3K-Akt pathways. Chem. Biological. interact. 160:23-133.

Leemans J, Cambier C, Chandler T, Billen F, Clercx C, Kirschvink N, Gustin P (2010). Prophylactic effects of omega-3 polyunsaturated fatty acids and luteolin on airway hyperresponsiveness and inflamma- 
tion in cats with experimentally-induced asthma. Vet. J. 184:111-114.

$\mathrm{Li} \mathrm{H}$, Chen B, Yao SZ (2005). Application of ultrasonic technique for extracting chlorogenic acid from Eucommia ulmodies Oliv. (E. ulmodies). Ultrason. Sonochem. 2:295-300.

Li HZ, Pordesimo L, Weiss J (2004). High intensity ultrasound-assisted extraction of oil from soybeans. Food. Res. Int. 37:731-738.

Liu R, Gao M, Qiang GF, Zhang TT, Lan X, Ying J, Du GH (2009). The anti-amnesic effects of luteolin against amyloid $\beta 25-35$ peptide-induced toxicity in mice involve the protection of neurovascular unit. Neurosci. 162:1232-1243.

Martino E, Ramaiola I, Urbano M, Bracco F, Collina S (2006) Microwave-assisted extraction of coumarin and related compounds from Melilotus officinalis (L.) Pallas as an alternative to Soxhlet and ultrasound-assisted extraction. J. Chromatogr. A. 1125:147-151.

PCCn (2010). Pharmacopoeia Committee of PR China, (2010 ed.).Chinese Pharmacopoeia, Beijing: Chemical Industry Publishing House. p. 351.

Pithayanukul P, Laovachirasuwan S, Bavovada R, Pakmanee N, Suttisri $\mathrm{R}$ (2004). Anti-venom potential of butanolic extract of Eclipta prostrata against Malayan pit viper venom. J. Ethnopharmacol. 90:347-352.

Roy RK, Thakur M, Dixit VK (2007). Development and evaluation of polyherbal formulation for hair growth-promoting activity. J. Cosmet. Dermatol. 6:108-112.
Samy RP, Gopalakrishnakone P. Ignacimuthu S (2006). Anti-tumor promoting potential of luteolin against 7,12-dimethylbenz(a)anthracene-induced mammary tumors in rats. Chem. Biol. interact. 164:1-14.

Stecher G, Huck CW, Stoggl WM, Bonn GK (2003). Phytoanalysis: a challenge in phytomics. Trends. Analyt. Chem. 22:1-14.

Wang XM, Zhang JS, Dai Y, Gao YT (2009). Study on extraction of flavone from Eclipta alba and its antioxidation in vitro. Lishiziien Med. Mater. Med. Res. 20:356-358.

Yang HY, Wang XM, Du G, Wang JP, Li GJ, Gao YT (2008a). HPLC determination of luteolin and apigenin in Herba Ecliptae. Lishiziien Med. Mater. Med. Res. 19:2994-2995.

Zhang M, Di XH, Liu M (1997). Immunomodulatory effects of flavonoids from Eclipta alba (L.) Hassk. Chinese traditional herbal drugs. 28:615.

Zhang LF, Liu ZL (2008). Optimization and comparison of ultrasound/microwave assisted extraction (UMAE) and ultrasonic assisted extraction (UAE) of lycopene from tomatoes. Ultrason. Sonochem. 15:731-737. 